\title{
An Ammonium Enrichment Event in the Surface Ocean: Wind Forcing and Potential \\ Ramifications
}

K.A. Fanninga ${ }^{\text {a }}$, R.T. Masserini ${ }^{\text {b }}$, J. Walsh ${ }^{\mathrm{a}}$, R. Wanninkhof ${ }^{\mathrm{c}}$, K. Sullivan ${ }^{\mathrm{c}}$, J.I. Virmani ${ }^{\mathrm{d}}$, \& C.A. Heil $^{\mathrm{e}}$

${ }^{\mathrm{a} C o r r e s p o n d i n g ~ A u t h o r, ~ C o l l e g e ~ o f ~ M a r i n e ~ S c i e n c e, ~ U n i v e r s i t y ~ o f ~ S o u t h ~ F l o r i d a, ~} 140$ Seventh Ave. S., St. Petersburg, FL 33701, USA, Telephone: 1-727-553-1130, Email: kaf@usf.edu

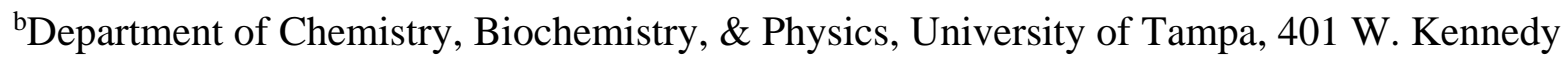
Blvd., Tampa, FL 33606, USA, Email: rmasserini@ut.edu

${ }^{\mathrm{c}}$ National Oceanic \& Atmospheric Administration (NOAA), Atlantic Oceanographic and Meteorological Laboratory (AOML), 4301 Rickenbacker Causeway, Miami, FL 33149, USA, Email: rik.wanninkhof@ noaa.gov or kevin.sullivan@ noaa.gov.

${ }^{\mathrm{d}}$ XPRIZE, 800 Corporate Pointe, Suite 350, Culver City, CA 90230, USA, Email:

Jyotika.Virmani@xprize.org

${ }^{\text {e} B i g e l o w ~ L a b o r a t o r y ~ f o r ~ O c e a n ~ S c i e n c e s, ~} 60$ Bigelow Drive, P.O. Box 380, East Boothbay

Harbor, ME 04544, USA, Email: cheil@bigelow.org 


\subsection{Introduction}

Processes affecting the nutrient regime within the ocean's euphotic zone are fundamental to upper-ocean carbon cycling (Eppley and Peterson, 1979). Even though photosynthetic carbon fixation in the euphotic zone is a major factor maintaining much of it in a nutrient-depleted (i.e., oligotrophic) condition, between one-third and one-half of the global-ocean export production occurs in oligotrophic regions (Sarmiento and Gruber, 2006). Therefore research continues on nutrient enrichments within oligotrophic euphotic zones. How often do enrichments occur? When and under what conditions do they occur, and how long do they last? Answers to these and other major questions about euphotic zone nutrients are often difficult to obtain due to the complexity of the zones and the problems involved in studying them.

Dissolved forms of nitrogen, phosphorus, and silicon are commonly considered to be principal plant nutrients in the sea because they provide the primary chemical elements required by organisms that can become limiting-- see Pilson (2013) and references therein. Which of these nutrients are more likely to be limiting is an ongoing question, but the major inorganic forms of nitrogen -- nitrate $\left(\mathrm{NO}_{3}^{-1}\right)$, nitrite $\left(\mathrm{NO}_{2}{ }^{-1}\right)$, and ammonium $\left(\mathrm{NH}_{4}{ }^{+1}\right)$ - appear more likely to be limiting at the spatial and temporal scales associated with metabolic processes (Sarmiento and Gruber, 2006). Ammonium is often a preferred nitrogen source for phytoplankton (McCarthy et al., 1977; Dortch, 1990). Our investigation focused on these three nitrogenous nutrients, and on ammonium in particular.

The euphotic zone selected for this nutrient-enrichment study was the West Florida Continental 
Shelf (WFS). Our data on surface $\left[\mathrm{NO}_{3}{ }^{-}\right],\left[\mathrm{NO}_{2}^{-}\right]$, and $\left[\mathrm{NH}_{4}{ }^{+}\right]$from six previous WFS cruises nearly always showed low values: mostly $<80$ nM (e.g., see Fig. 8 of Masserini and Fanning (2000)). Interestingly, the vertical $\mathrm{NH}_{4}{ }^{+}$concentration pattern in the upper $150 \mathrm{~m}$ at the Bermuda Atlantic Time-series Study (BATS) site shows essentially the same range of values as on the WFS (see Fig. 3 of Lipschultz (2001). Zero-to-80 nM appears to indicate un-enriched WFS water (section 3.1).

The goals of our research were 1) to characterize nitrate, nitrite, and ammonium enrichments in the low-nutrient WFS euphotic zone in terms of location, magnitude, duration, and associated environmental parameters and 2) to investigate the role that physical processes might play in the formation and/or destruction of these enrichments.

\subsection{Methods and Experimental Design}

Field research on nitrate, nitrite, and ammonium in oligotrophic waters requires specially adapted techniques. First, the low, nanomolar concentrations of the three nutrients in WFS waters require analytical methods with greater sensitivities than conventional ones (e.g., Grasshoff, 1976; Gordon et al., 1993). Second, determining the physical details of near-surface seawater boluses containing nutrient enrichments requires that sampling be conducted on horizontal spatial scales well below the kilometer range. Third, evaluation of the changes in nanomolarscale nutrient enrichments requires surveys of near-surface waters over longer time spans. 
Fourth, knowledge of the kinetics of in situ reactions between nutrients and biota is needed in order to estimate the lifetimes of those enrichments.

Several special experimental protocols and methods were utilized. The Masserini and Fanning (2000) high-sensitivity fluorometric system, designed for euphotic zones with detection limits $\leq 10 \mathrm{nM}$, provided nitrate, nitrite, and ammonium concentrations in the upper two meters of the WFS water column at known positions on the order of 300 meters apart during surface surveys. Sulfur hexafluoride $\left(\mathrm{SF}_{6}\right)$ tracer (Wanninkhof et al., 1997) provided the ability to track nutrients within a seawater patch in time and space. Measured nutrient consumption and production rates (Mulholland et al., 2006; Bronk et al., 2014) provided in situ reaction rates for use in evaluating enrichment durations. Finally, meteorological data were used to assess the impact that weatherrelated processes might have on euphotic-zone nutrients.

Two Lagrangian field experiments were conducted in the WFS euphotic zone (Fig. 1). This zone is similar to the oligotrophic central gyres of the ocean basins in that WFS nutrients are scarce and often limit phytoplankton growth (Vargo et al., 2008). Phytoplankton communities in oligotrophic regions are generally believed to persist through the use of recycled nutrients (e.g. Eppley et. al., 1973 and Kiefer and Atkinson, 1984). The two experiments -- FSLE V and FSLE VI of the series of Florida Shelf Lagrangian Experiments started by Wanninkhof et al. (1997) -were conducted during the drier, cooler season of the year when northwesterly weather fronts pass through the area (see Sections 3.2,3.3, and 4.2.1). 
Each experiment began with an initial survey southward from C10 (Fig. 1) until a nutrient peak or enrichment was encountered in a patch of $\mathrm{SF}_{6}$-free seawater. At that point $\mathrm{SF}_{6}$ was injected (Wanninkhof et al., 1997) into the patch as a label or tracer in order to guarantee that nutrient surveys maintained contact with the patch as it drifted and mixed with the surrounding seawater. Spatial and temporal variations in surface nutrient concentrations were then followed from the $R / V$ F.G. Walton Smith in a zigzag pattern of survey transects at three knots $\left(5.6 \mathrm{~km} \mathrm{~h}^{-1}\right)$ across the patch into the surrounding seawater and back. During each transect, regular measurements were made of $\left[\mathrm{SF}_{6}\right]$ and of $\left[\mathrm{NH}_{4}{ }^{+}\right],\left[\mathrm{NO}_{3}{ }^{-}\right]$, and $\left[\mathrm{NO}_{2}^{-}\right]$according to the procedures of Wanninkhof et al. (1997) and Masserini and Fanning (2000), respectively. These measurements were conducted on sub-samples of a stream of seawater drawn from the upper $2 \mathrm{~m}$ through a port in the ship's hull into its scientific seawater system. Also, two-to-four times per day, vertical distributions of nutrients, $\mathrm{SF}_{6}$, temperature, salinity, and chlorophyll were obtained from conductivity-temperature-depth (CTD) hydrocasts near the locus of the highest surface $\mathrm{SF}_{6}$ concentrations within the patch -- i.e., its center. Nutrient and $\mathrm{SF}_{6}$ concentrations in the hydrocasts were determined on seawater samples from the CTD rosette by the methods mentioned, and vertical temperature, salinity, and chlorophyll profiles were determined by sensors on the CTD.

Detection of concentrations of "total dissolved ammonia" during at-sea experiments is greatly improved by the fluorescence technology in the Masserini and Fanning (2000) nutrient system. Its ammonium module utilizes a variation of the Jones (1991) fluorescent ammonium method and is operated simultaneously with the fluorescent, aniline-based modules for nitrate and nitrite devised by Masserini and Fanning. The $\mathrm{NH}_{3}$ molecule exists in two forms in seawater: dissolved 
ammonia gas $\left(\mathrm{NH}_{3}(\mathrm{aq})\right)$ and dissolved ammonium ion $\left(\mathrm{NH}_{4}{ }^{+}\right)$, and the Jones (1991) method converts $\mathrm{NH}_{4}{ }^{+}$to $\mathrm{NH}_{3}$ (aq) in order to ensure that all of the ammonia dissolved in a seawater sample is detected. Thus "ammonium" or " $\mathrm{NH}_{4}+$ " in this report is equivalent to "total dissolved ammonia.”

The Masserini-Fanning system software acquired one seawater sample every $200 \mathrm{sec}$ which, when combined with a ship's speed of $\sim 3$ knots $\left(\sim 5.6 \mathrm{~km} \mathrm{~h}^{-1}\right)$, resulted in one discrete determination of $\left[\mathrm{NO}_{3}^{-1}\right],\left[\mathrm{NO}_{2}^{-1}\right]$, and $\left[\mathrm{NH}_{4}{ }^{+1}\right]$ approximately every 300 meters along each survey transect. The nutrient system was close enough to the side of the vessel that sample dwell time from the intake port was negligible. The software also provided the GPS-based coordinates of each sample, thus permitting estimates of the size, shape, and locations of nutrient enrichment peaks. Corresponding [SF6] values by the Wanninkhof et al. (1997) approach were obtained from the scientific seawater stream with similar spatial and temporal resolutions.

Large numbers of surface water samples were analyzed for $\left[\mathrm{NO}_{3}^{-1}\right],\left[\mathrm{NO}_{2}^{-1}\right]$, and $\left[\mathrm{NH}_{4}{ }^{+1}\right]$. In FSLE V, two Masserini-Fanning instruments, operating simultaneously, analyzed a total of 4321 samples. In FSLE VI, one instrument was used to analyze 2636 samples.

3.0 Results

3.1 Examples of ammonium and $\mathrm{SF}_{6}$ distributions in time and space 
The $\mathrm{SF}_{6}$ label in a seawater patch is not uniformly distributed but is found in smaller boluses of seawater within the patch. In a survey transect from FSLE V (Fig. 2a), one such bolus contains a strong $\left[\mathrm{NH}_{4}{ }^{+1}\right]$ enrichment, another a weaker secondary enrichment, and the third no enrichment. Such patterns are typical. $\left[\mathrm{NH}_{4}{ }^{+1}\right]$ enrichment peaks can be initially present or arise after the $\mathrm{SF}_{6}$ label has been injected. Fig. 2a also shows that the background $\left[\mathrm{NH}_{4}{ }^{+1}\right]$ between $\left[\mathrm{NH}_{4}{ }^{+1}\right]$ enrichment peaks lies below $100 \mathrm{nM}$ and is principally $<50 \mathrm{nM}$, in agreement with statements in section 1.0. This finding is consistent with the conclusion that the normal background $\left[\mathrm{NH}_{4}{ }^{+1}\right]$ on the WFS was 0-80 nM (see also Section 4.1). Fig. 2b displays the horizontal distribution of $\left[\mathrm{NH}_{4}{ }^{+1}\right]$ enrichments in the upper $2 \mathrm{~m}$ of the transect in Fig. 2a. The strong enrichment is separated from the weaker enrichment by 63 minutes in time and by $1770 \mathrm{~m}$ in distance along a great circle.

\subsection{FSLE V}

$\mathrm{SF}_{6}$ injection (Wanninkhof et al., 1997) for FSLE V occurred at 2200 GMT on 18 April 2001 -Julian Day (JD) 108 -- at $26.964^{\circ} \mathrm{N}, 82.821^{\circ} \mathrm{W}$ (Fig. 1). FSLE V was thus conducted at the end of the season of drier, cooler weather that occurs annually in the Gulf of Mexico. Surveys began on JD 110 (Fig. 3), when the highest $\mathrm{SF}_{6}$ concentrations in the labeled seawater were clustered in a locus with $\mathrm{SF}_{6}$ values $\geq 400$ parts per trillion (pptr by volume). As the $\mathrm{SF}_{6}$-labeled seawater mixed with adjacent $\mathrm{SF}_{6}$-free seawater, $\mathrm{SF}_{6}$ concentrations decreased within that locus, mostly due to dispersion, and followed the trend predicted from wind speeds by Wanninkhof et al. (1997). Water depth was $25 \mathrm{~m}$ (see color-coding in Fig. 1). 
No surface $\left[\mathrm{NH}_{4}^{+}\right]$enrichments were initially encountered (Fig. 3c). From JD 110 through most of JD 111, $\left[\mathrm{NH}_{4}^{+}\right]=0-80 \mathrm{nM}$. The first $\left[\mathrm{NH}_{4}^{+}\right]$maximum above this background range (Section 4.1) was detected as a $206 \mathrm{nM}$ peak on JD 111.9. Ammonium maxima of similar or greater magnitude then became prominent at the surface of the $\mathrm{SF}_{6}$-labeled seawater patch until JD 116 when such $\left[\mathrm{NH}_{4}{ }^{+}\right]$enrichments could no longer be detected, even though the survey protocol continued for another $2 \frac{1}{2} 2$ days until JD 118.5. The largest observed $\left[\mathrm{NH}_{4}^{+}\right]--434 \mathrm{nM}$ just before JD 115 -- was five times greater than $80 \mathrm{nM}$, the upper bound of the background range. The high frequency of strong $\mathrm{NH}_{4}{ }^{+}$enrichments between JD 111.9 and JD 116 constitute an ammonium event, which occurred despite the fact that the $\mathrm{SF}_{6}$-free seawater diluting the $\mathrm{SF}_{6}$ in the labeled seawater was also mixing in low, background-level $\left[\mathrm{NH}_{4}^{+}\right]$.

Ammonium data from twenty-four FSLE V CTD hydrocasts were consistent with the surface surveys. Fig. 4 presents the time course of water-column ammonium at the center of the $\mathrm{SF}_{6}$ labeled patch, i.e., the locus of the highest $\left[\mathrm{SF}_{6}\right]$ in the patch. Out of 200 water samples from these hydrocasts, nineteen had enriched $\mathrm{NH}_{4}{ }^{+}$concentrations ( $200 \mathrm{nM}$ to $492 \mathrm{nM}$ ), but these enrichments primarily occurred between JD 112 and JD 116, when the surface maxima were detected (Fig. 3c).

The FSLE V ammonium event was thus not exclusively a surface phenomenon. The deeper subsurface ammonium maxima had vertical thicknesses of at least $5 \mathrm{~m}$ in most cases (Fig. 4). The strongest surface and deeper ammonium enrichments shown in Fig. 3c and Fig. 4, respectively, occurred during the period of decreasing wind speeds and barometric pressure -- JD 112 to JD 116 in Figs. 3a and 3b. By the time of the wind-speed maximum on early JD 117 in 
Fig. 3a, the ammonia maxima in the surface water (Fig. 3c) and in the deeper water column (Fig. 4) had disappeared. Conditions at sea were too rough to permit CTD sampling of the water column between JD 117.07 and JD 118.81, which explains why the disappearance of the subsurface maxima is not better defined.

In contrast to $\left[\mathrm{NH}_{4}^{+}\right]$, nitrate and nitrite during FSLE V showed little pronounced variation; $\left[\mathrm{NO}_{3}{ }^{-}+\mathrm{NO}_{2}^{-}\right]$mostly remained between 50 and $80 \mathrm{nM}$, in agreement with Masserini and Fanning (2000). Two peaks above this range (117 $\mathrm{nM}$ at JD 109.8, 135.7 $\mathrm{nM}$ at JD 111.3) appeared before the ammonium event, but no $\left[\mathrm{NO}_{3}{ }^{-}+\mathrm{NO}_{2}{ }^{-}\right]$above this range appeared thereafter.

\subsection{FSLE VI}

To investigate the ammonium-event phenomenon further, the second Lagrangian experiment (FSLE VI) was performed 11/2 yr later. On 5 November 2002 (JD 309), SF6 was injected (Wanninkhof et al., 1997) into another patch of surface Gulf-of-Mexico seawater, this time at $26.537^{\circ} \mathrm{N}, 82.783^{\circ} \mathrm{W}$ (Fig. 1). FSLE VI protocol closely duplicated FSLE V protocol, the major difference being that FSLE VI was conducted at the beginning instead of the end of the season of drier, cooler weather that occurs annually in the Gulf of Mexico. Experimental lengths were similar: 8 days for FSLE VI vs. 8.5 days for FSLE V.

Surface FSLE VI ammonium results differed considerably from FSLE V ammonium results (Fig. 5c vs. Fig. 3c). Sampling for FSLE VI nutrients began at JD 310.8, and the initial ammonium values (50-130 nM) were somewhat above background (Fig. 5c). A $\left[\mathrm{NH}_{4}^{+}\right]$peak $(211 \mathrm{nM})$ 
appeared on JD 311.5, followed by a weaker peak (185 nM) 24 hours later on JD 312.5. Wind speeds during this period ranged from 4-to- $14 \mathrm{~ms}^{-1}$ (Fig. 5a). At the $211 \mathrm{nM}$ peak, wind speeds began a decline, with most values being $<10 \mathrm{~ms}^{-1}$. Then at JD 317.4 sharp increases above 20 $\mathrm{ms}^{-1}$ occurred, followed by decreases back to $10 \mathrm{~ms}^{-1}$ or less. After the $185 \mathrm{nM}$ peak at JD 312.5, ammonium values remained between 0 and $130 \mathrm{nM}$ for two days and then were essentially at background (0-80 nM, Sections $1,3.1$, and 4.1) thereafter. Unlike FSLE V, FSLE VI showed no ammonium event. During the time of declining wind speeds between JD 311.5 and JD 317.4, (Fig. 5a), there was no cluster of strong ammonium maxima (Fig. 5c).

CTD hydrocasts yielded subsurface data consistent with the low surface $\left[\mathrm{NH}_{4}^{+}\right]$during FSLE VI. Fig. 6 presents the time course of ammonium in the water column at the center of the FSLE VI $\mathrm{SF}_{6}$ patch. Similar to the surface water data, no high subsurface ammonium concentrations (i.e., much greater than $211 \mathrm{nM}$ ) were found. The highest subsurface $\left[\mathrm{NH}_{4}{ }^{+}\right]$was only $121 \mathrm{nM}$. It occurred during JD 312-JD 315 when wind speeds were declining (Fig. 5a), and the entire water column had slightly elevated $\left[\mathrm{NH}_{4}^{+}\right]$(Fig. 6). Subsurface $\left[\mathrm{NH}_{4}^{+}\right]$was at background between JD 315 and JD 316.8. Conditions at sea were too rough to permit CTD sampling of the water column on Julian Days 317 and 318. As a result, no subsurface data points were obtained during this time period, which corresponds to the period of the highest wind speeds (Fig. 5a) and the lowest surface ammonium concentrations for FSLE VI (Fig. 5c). For details about the FSLE VI $\left[\mathrm{NH}_{4}{ }^{+}\right]$trends in Figs 5c and 6, see Section 4.3. 
Nitrate and nitrite during FSLE VI behaved in a fashion similar to that observed during FSLE V - i.e, very little change. Values of $\left[\mathrm{NO}_{3}{ }^{-}+\mathrm{NO}_{2}{ }^{-}\right]$during FSLE VI ranged from 0 to $55 \mathrm{nM}$ in both the surface survey transects and in subsurface waters sampled by hydrocasts.

\subsection{Discussion}

\subsection{Statistics of Measured Parameters}

A single factor ANOVA analysis was applied to determine whether or not the populations of the values of five measured parameters were statistically different between FSLE V and FSLE VI (Table 1). The highest confidence interval (99.9\%) was chosen, and the $F_{\text {critical values were }}$ 10.83. Three parameters (Wind Speed, Temperature, and Total Ammonia) were statistically different, and two parameters (Salinity and Chlorophyll) were not statistically different.

The fact that the wind-speed Factor $(124,127)$ is larger than $F_{\text {critical }}(10.83)$ is evidence that the wind-speed regime of FSLE VI was different from that of FSLE V. The weather front was stronger in FSLE VI than in FSLE V (for details, see Sections 4.2.1 and 4.2.2).

Temperatures on FSLE VI $\left(26.32-27.42^{\circ} \mathrm{C}\right)$ were on average $5.6^{\circ} \mathrm{C}$ warmer than on FSLE V $\left(19.62-22.70^{\circ} \mathrm{C}\right)--$ a clear difference. The upper $25 \mathrm{~m}$ of the WFS water column at the beginning of the drier, cooler season may have had some residual heat from the wetter, warmer season (May to September). Warmer FSLE VI temperatures might have stimulated some ammonia outgassing, but might have led to even faster rates of ammonium production from organic-matter 
remineralization by WFS biota. Also, strong FSLE VI winds may have enhanced ammonium levels by means of near-bottom turbulence (Section 4.3).

The principal observations of our field study were the ammonium event during FSLE V and the lack of an ammonium event in FSLE VI. The finding that the FSLE V and FSLE VI populations of ammonium data are statistically different is consistent with these observations (Figs. 3c and 4 vs. Figs. 5c and 6).

The mean $\left[\mathrm{NH}_{4}{ }^{+}\right]$for the survey data in the upper $2 \mathrm{~m}$ of FSLE V was $23.8 \pm 25.5 \mathrm{nM}$ where $25.5 \mathrm{nM}$ is the standard deviation $(\sigma)$ of the FSLE V $\left[\mathrm{NH}_{4}^{+}\right]$population. At a confidence level of $95.4 \%$, most of the $\left[\mathrm{NH}_{4}{ }^{+}\right]$values would fall in the range $23.8 \pm 2 \sigma \mathrm{nM}$, or $23.8 \pm 51.0 \mathrm{nM}$. To be classified as maxima $\left[\mathrm{NH}_{4}{ }^{+}\right]$should be $>23.8+51.0 \mathrm{nM}=74.8 \mathrm{nM}$, which supports the selection of 0-80 nM as the background range for $\left[\mathrm{NH}_{4}^{+}\right]$on the WFS (Sections 1 and 3.1).

The finding that salinity and chlorophyll were not statistically different is consistent with the fact that the two experiments were conducted in the same season of the year - the cooler, drier months between October and April when northwesterly weather fronts pass across the WFS. The salinities were high -- FSLE V: $36.438 \pm 0.432(\sigma)$ vs. FSLE VI: $36.342 \pm 0.354(\sigma)$. Chlorophyll was low -- FSLE V $\left(0.08-0.60 \mu \mathrm{g} \mathrm{l}^{-1}\right)$ vs. FSLE VI $\left(0.07-0.41 \mu \mathrm{g}^{-1}\right)$, and there were no strong red tides to alter nutrient processes (Mulholland et al. 2006).

4.2 Meteorological Parameters 


\subsubsection{Temporal Trends}

During FSLE V, variations in meteorological parameters, as measured on shipboard (Fig. 3a and b) and confirmed by instruments on mooring C10 (Fig. 1), appear to be linked to the presence or absence of $\left[\mathrm{NH}_{4}{ }^{+}\right]$maxima (Fig. 3c and Fig. 4). From JD 110 through part of JD 111, wind speeds were mostly $\sim 1 \mathrm{~ms}^{-1}$ to $\sim 7 \mathrm{~ms}^{-1}$ (Fig. 3a), while barometric pressure was $1022-1027 \mathrm{mb}$ (Fig. 3b). But, near the end of JD 111, both parameters began to change. Wind speeds decreased, with minimum values becoming $\leq 1 \mathrm{~ms}^{-1}$ for increasingly long periods of time and maximum wind speeds declining, eventually to $\leq 4 \mathrm{~ms}^{-1}$ at JD $114-116$. Barometric pressure decreased to 1014 -1019 mb. Then both wind speed and barometric pressure increased rather sharply, mostly during JD 116. These wind-speed and barometric-pressure patterns indicate the approach and passage of a low-pressure weather front (Virmani and Weisberg, 2005). The period of calming winds ahead of the front was of particular interest because it matched so well with the period in which the strong surface and subsurface $\left[\mathrm{NH}_{4}^{+}\right]$maxima were present -- i.e., the ammonium event in JD 112-116 (Section 3.2). When wind speeds and barometric pressure subsequently increased during frontal passage, both the maxima and the event disappeared.

Winds generate sea-surface wind stress, enhancing turbulence. The natural aggregation of planktonic organisms into patches is well known (Martin, 2003). These planktonic patches would not necessarily coincide with the $\mathrm{SF}_{6}$ patches (section 3.1) but are more likely to be associated with boluses containing ammonium enrichments. Ammonium concentrations should be higher in seawater abundant with bacteria and other organisms, such as microzooplankton grazers, that cause ammonium release through organic-matter remineralization. Higher wind 
speeds lead to greater wind stress and should produce more intense mixing between such boluses and the surrounding seawater, resulting in the dispersion of the organisms and the dilution of the ammonium concentrations.

As wind speeds weaken preceding an approaching low-pressure front, mixing should also weaken, and the concentrations of the remineralization-producing organisms and the $\mathrm{NH}_{4}{ }^{+}$they release might be expected to increase within planktonic patches, leading to peaks in $\left[\mathrm{NH}_{4}{ }^{+}\right]$such as in Fig. 2a for FSLE V. Distances across these peaks, estimated from the positions of the beginnings and endings of the peaks, were 1.1-4.4 km, or in the low end of the mesoscale/submesoscale range $(1-100 \mathrm{~km})$ that describes observable features like filaments, eddies, etc. (Martin, 2003).

Wind behavior could explain the disparity between FSLE V results and FSLE VI results, even though a preliminary examination suggests that the weather patterns of FSLE VI (Fig. 5) in fact resembled those of FSLE V (Fig. 3). In Fig. 5 ( $a$ and b) the decline of wind speed and barometric pressure between JD 311.5 and JD 317, followed by strong increases in both parameters, clearly denotes the approach and passage of a weather front during FSLE VI, just as seen in Fig. 3 (a and b) during FSLE V. Thus, FSLE VI might have been expected to exhibit an ammonium event with $\left[\mathrm{NH}_{4}^{+}\right]$maxima $\approx 400 \mathrm{nM}$. However, closer inspection reveals a fundamental difference: FSLE VI wind speeds were considerably higher than FSLE V wind speeds. (Notice the difference in the wind-speed scales between Figs. 3a and 5a). FSLE V wind speeds frequently dropped to zero, especially during JD 114-116, when the ammonium peaks were particularly strong (Fig. 3c), and were never above $8.2 \mathrm{~ms}^{-1}$. In contrast, FSLE VI wind 
speeds were often $>10 \mathrm{~ms}^{-1}$, and even reached $15-22 \mathrm{~ms}^{-1}$ (Fig. 5a). FSLE VI winds should have had much greater dispersive effects than FSLE V winds (section 4.2.2).

\subsubsection{Quantitative Comparison of FSLE V and FSLE VI Wind Regimes}

The interactions of wind with the sea surface can be quite sensitive to differences in wind forcing. Sea-surface wind stress typically varies with the magnitude of the wind speed raised to a power on the order of two (Neumann and Pierson, 1966). After SF6 injection to create an SF6 patch, $\mathrm{SF}_{6}$ concentration will decline within the patch because of atmospheric gas exchange and dispersion, which mixes $\mathrm{SF}_{6}$-labeled water with water in which $\left[\mathrm{SF}_{6}\right]$ is zero. The decrease in $\left[\mathrm{SF}_{6}\right]$ due to air-water gas transfer can be quantified from the relationship of gas transfer with wind speed. The difference between the measured total concentration decrease and the decrease due to gas transfer is the decrease caused by dispersion.

The effect of gas transfer on concentration (via first-order kinetics) can be represented by a residual fraction $\left(f_{\mathrm{exch}}\right)$, which expresses the ratio of the $\left[\mathrm{SF}_{6}\right]$ after reduction by gas exchange to the $\left[\mathrm{SF}_{6}\right]$ initially present:

$$
f_{\text {exch }}=\exp \left(k \cdot h^{-1} \cdot \mathbf{t}\right)
$$

Here "k" is the gas transfer velocity of SF6 related to wind speed (Wanninkhof, 1992), " $h$ " is the mixed layer depth (25 $\mathrm{m}$ in Fig. 1), and "t" is the time interval. The measured fraction of the original concentration of $\mathrm{SF}_{6}$ that remains after time " $\mathrm{t}$ " $\left(f_{\text {total }}\right)$ is given by: $f_{\text {total }}=f_{\text {exch }} \bullet f_{\text {disp }}$ where $f_{\text {disp }}$ is the ratio of the $\left[\mathrm{SF}_{6}\right]$ after dispersion to the $\left[\mathrm{SF}_{6}\right]$ initially present. Therefore,

$$
f_{\text {disp }}=f_{\text {exch }} \cdot\left(f_{\text {total }}\right)^{-1}=\left[\exp \left(\mathrm{k} \cdot \mathrm{h}^{-1} \cdot \mathrm{t}\right)\right] \cdot\left(f_{\text {total }}\right)^{-1}
$$


This dispersion will also alter the $\left[\mathrm{NH}_{4}^{+}\right]$values within the patch if the surrounding seawater has different $\left[\mathrm{NH}_{4}{ }^{+}\right]$values. $\mathrm{SF}_{6}$ can thus serve as a "proxy" for $\mathrm{NH}_{4}{ }^{+}$in evaluating the effects of dispersion, once corrections for $\mathrm{SF}_{6}$ gas exchange are applied. As discussed below concerning the work of Johnson et al. (2008), ammonium concentrations are not impacted by the gasexchange process with the atmosphere at the time scales considered here (Section 4.3). So the only physical process that reduces ammonium concentration is dispersion, and values for $f_{\text {disp }}$ derived from $\mathrm{SF}_{6}$ (Eq. 2) can be used. The [SF6] values used in Eq. (1) and Eq. (2) were obtained from the $\mathrm{SF}_{6}$ measurements at the centers of the patches at different times during FSLE $\mathrm{V}$ and FSLE VI.

Consistent with the statistically different wind regimes in FSLE V and VI (Section 4.1), a comparison of the trends of $\ln f_{\text {disp }}$ with time for $\mathrm{SF}_{6}$ demonstrates the distinctly different levels of dispersion in the two experiments (Fig. 7). Calculations based on the least-squares approximations in the figure indicate that, after 3 days, the fraction of the $\mathrm{SF}_{6}$ remaining in the center of the $\mathrm{SF}_{6}$ patch was $\sim 2$ times greater in FSLE V than in FSLE VI. After 6 days, the fraction was $\sim 4$ times greater in FSLE V than in FSLE VI, and after 9 days it was $\sim 9$ times greater in FSLE V than in FSLE VI. The greater dispersion in FSLE VI affected both [SF6] and $\left[\mathrm{NH}_{4}^{+}\right]$.

The contours of potential density anomaly for FSLE VI (Fig. 6) were largely vertical whereas the same contours for FSLE V (Fig. 4) were more horizontal and more closely packed. This difference suggests that stronger winds in FSLE VI made the water column more turbulent, such 
that water-column stability was reduced compared to FSLE V. A greater FSLE V stability would support greater plankton aggregations and higher ammonium concentrations.

4.3 Duration and Possible Sources and Sinks for the Ammonium Maxima and Enrichments

Since ammonium is such a critical nutrient (Section 1), might not the phytoplankton during FSLE V have consumed remineralized ammonium as fast as it appeared? Ammonium uptake rates by phytoplankton measured in those waters during 2001-2002 - see Table 6 of Mulholland et al. (2006) -- can be used to estimate the duration times of the FSLE V ammonium maxima. The Mulholland et al uptake rates ranged from 6 to $86 \mathrm{nM} \mathrm{hr}^{-1}$ when the red-tide organism $K$. brevis was absent (as was true during FSLE V). The largest surface FSLE V ammonium maximum was $434 \mathrm{nM}$, or $354 \mathrm{nM}$ above the upper bound of the background concentration: 80 $\mathrm{nM}$ (Section 4.1). Thus, if we assume that no ammonium production occurred, the maximum would have been reduced to background in $t=354 \mathrm{nM} /\left(6\right.$ to $\left.86 \mathrm{nM} \mathrm{hr}^{-1}\right)=4.1$ to $59 \mathrm{hr}$. Similarly, a FSLE V ammonium maximum of $200 \mathrm{nM}$ is $120 \mathrm{nM}$ above the same background and would have been reduced to background in $t=1.4$ to $20 \mathrm{hr}$. These ranges provide estimates of the duration times of the ammonium maxima in FSLE V, but are most likely too low since ammonium production was ignored. Indeed, isotopic measurements by Bronk et al. (2014) - see their Table 4 -- indicated that in 2007 and 2008 some of the ammonium production rates by regeneration plus some minimal photoproduction (150-180 $\mathrm{nM} \mathrm{hr}^{-1}$ ) were larger than ammonium uptake rates for red-tide-free waters in the same area, thus supporting the possibility of longerlived ammonium peaks. 
The field-sampling protocol utilizing the Masserini-Fanning (2000) system was able to transect all ammonium peaks in 0.17 to $0.97 \mathrm{hr}$. Since these transit times are much smaller than the estimated peak duration times, ammonium uptake by primary producers was not rapid enough to prevent the peaks from being detected.

Another question concerns the source(s) of the ammonium in the maxima observed during FSLE V, once again keeping in mind that no red tide (i.e., K. brevis) was present. Within the water column, the two most likely sources are dissolved organic nitrogen (DON) and particulate organic nitrogen (PON). DON concentrations determined by the Solorzano and Sharp (1980) and Valderama (1981) methods in the same Gulf of Mexico surface waters in 2002 (when red tides were also absent) averaged $8300 \pm 1200 \mathrm{nM}$. Although no DON values were measured during 2001, the 2002 results matched reasonably well with later DON results for the same waters when red tide was absent in 2004: $9100 \pm 500 \mathrm{nM}$. So it would be reasonable to assume that the DON concentration in the FSLE V experimental area is typically $~ 8000 \mathrm{nM}$ in the absence of red tide. Next, data on PON from CHN analyses in April 2001 averaged $3250 \pm 1750$ $\mathrm{nM}$, making the estimated total concentration of DON + PON during FSLE V equal to 11,250 nM. Thus an ammonium release sufficient to produce the highest observed ammonium enrichment above background during FSLE V (354 nM) would have required that only 3\% of the total available organic nitrogen in the water column be remineralized by ammonifying organisms.

Johnson et al. (2007) proposed that ammonium could be released when a silica-limited diatom bloom experiences a decline and is replaced by non-siliceous primary producers. Could the 
FSLE V ammonium event be a result of a similar process? Studies on chlorophyll and phytoplankton species distributions in the Eastern Gulf of Mexico near FSLE V (G. Kirkpatrick, MOTE Marine Laboratory, pers. comm.) provided no evidence for diatom blooms between February and April of 2001. Chlorophyll values among diatoms during this period were low: 0$0.2 \mu \mathrm{g} \mathrm{l^{-1 }}$.

The ammonium-enriched waters had high, pelagic salinities (Section 4.1), suggesting that the enrichments did not come from terrestrial fresh waters. Also, no substantive increases in ammonium were observed in portions of the survey transects that were closer to the Florida landmass to the east (Fig. 1). So freshwater runoff as a source of FSLE V ammonium enrichment is unlikely.

Could wet deposition from the atmosphere have provided the principal source of ammonium for the FSLE V maxima? The answer is most likely "no." The largest maxima appeared when the wind speeds were very low, i.e., before the storm associated with the weather front actually arrived (section 4.2.1). Also, the summary of nitrogen sources that might support K. brevis or other phytoplankton on the WFS in Table 9 of Vargo et al. (2008) indicates that, on average, the largest source was zooplankton excretion (which is a remineralization process). Atmospheric deposition was almost three orders of magnitude smaller.

Could ammonium maxima arise via exchanges across the sediment-water interface? In the case of FSLE V, the time course of ammonia maxima in the water column (Fig. 4) shows few maxima that appear to contact the sea floor, as should be expected if the sea floor is a source. However, 
in the case of FSLE VI, its strong winds may have enhanced near-bottom turbulence, particularly between JD 312 and JD 315. Ammonium release because of this turbulence might help to explain the slightly higher $\left[\mathrm{NH}_{4}{ }^{+}\right]$on the surface (Fig. 5c) and throughout the water column (Fig. 6) until JD 315. After JD 315, $\left[\mathrm{NH}_{4}{ }^{+}\right]$essentially returned to background (0-80 nM), at least until the really strong winds at JD 317.4 (Fig. 5a), for which no data could be collected (Fig. 6).

A study of air-sea exchanges of $\mathrm{NH}_{3}$ (g) by Johnson et al. (2008) raises the issue that these exchanges might be atmospheric sources for dissolved ammonium in the upper ocean. Johnson et al. estimated the magnitudes and directions of $\mathrm{NH}_{3}(\mathrm{~g})$ exchanges at different latitudes and temperatures in the Atlantic and concluded that warm ocean temperatures at latitudes of 20$30^{\circ} \mathrm{N}$, such as encountered at FSLE V and VI, tended to make seawater a net source of $\mathrm{NH}_{3}(\mathrm{~g})$ to the atmosphere. Their conclusion suggests that the atmosphere could not have been the source of FSLE V ammonium maxima.

But could the upward ammonium fluxes have caused a reduction in the magnitudes and durations of the maxima in FSLE V? A typical upward flux for $20-30{ }^{\circ} \mathrm{N}$ latitude is $50 \mathrm{pmol} \mathrm{m}^{-2} \mathrm{~s}^{-1}$-- Fig 6 and Fig 7 of Johnson et al. (2008), which would reduce the ammonium concentration in the top cubic meter of a well-mixed water column by approximately $4 \mathrm{nM}$ per day. However, the CTD hydrocasts conducted during FSLE V found that the thicknesses of the boluses containing ammonium enrichments during the ammonium event were on the order of 5 meters -- Fig. 4 in Section 3.1 (above). Therefore, if we assume that the upward ammonium flux affects the total ammonium concentration in the upper 5 meters of a well-mixed water column, it would deplete that concentration at a rate of $0.86 \mathrm{nM}$ per day. This sea-to-air flux of $\mathrm{NH}_{3}(\mathrm{~g})$ would then require 
400 days to deplete the largest maximum above background in FSLE V (354 nM). A doubled flux would require 200 days to deplete the 354 nM FSLE V maximum. Since the lifetimes of the maxima during the FSLE V ammonium event appear to have been 5 days or less, the magnitudes and time scales of the upward air-sea ammonium fluxes estimated by Johnson et al. would appear to be too small to have had a meaningful impact on the FSLE V ammonium maxima. This finding supports the assumption that loss of ammonium to the atmosphere is negligible when using Eq. 2 in Section 4.2.2 (above) to compare FSLE V and VI dispersion coefficients, $f_{\text {disp. }}$

Could the ammonium enrichments have been supplied by upwelled deep water that rose above the shelf break and mixed with the 25-m water column where the FSLE V experiment took place (Fig. 1)? Enrichments due to upwelling are nearly impossible for two reasons. First, the West Florida Shelf (WFS) is over $200 \mathrm{~km}$ wide where FSLE V and VI were conducted (Yang and Weisberg, 1999), and the ammonium injection points were over $150 \mathrm{~km}$ shoreward of the shelf break. Water movement on the shelf in this region is primarily driven by meteorological events and tides (Wanninkhof et al., 1997, Yang and Weisberg, 1999). Although this region is upwelling-favorable from October to April (Liu and Weisberg, 2012), the large expanse of shelf between the experiment location and shelf edge make cross-shelf transport of deepwater of any sort unlikely (Olascoaga et al., 2006). Second, and perhaps more importantly, the available published data suggest that deep-water ammonium concentrations are very low, $\sim 40-65 \mathrm{nM},--$ Woodward and Rees (2001). So, even in the unlikely event that deep water was transported onto the WFS, it would not be able to enrich the upper $25 \mathrm{~m}$ of the surface waters in ammonium. 


\subsection{Potential Ramifications}

The implication of these results relates to the mechanism of recycled primary production in the ocean, for which ammonium is critical. The possibility that weakening winds could lead to ammonium enrichments over time periods of days suggests a mechanism whereby planktonic primary producers might, in effect, receive localized ammonium "supplements" that then stimulate photosynthesis, and thus carbon fixation rates.

Wind-influenced ammonium enrichments in the eastern Gulf of Mexico could be rather frequent. For example, each year that region receives on average 7-8 winter weather fronts (Virmani and Weisberg, 2005) such as observed in FSLE V and VI, and 24-hour, low-pass filtered hourly wind-speed data from the nearby COMPS current mooring C10 (Fig. 1) established that wind speeds persisted below $4 \mathrm{~ms}^{-1}$ for two days or more 72 times in 2001, suggesting ample opportunities during a year for calming winds to permit ammonium accumulation. Sixty-four percent of these opportunities occurred in May-September -- the warmer and wetter season of the year, when biota growth is greater. Also, the distance scales of wind patterns are many-fold larger than the $\mathrm{SF}_{6}$ patches in FSLE V; so it is reasonable to assume that ammonium enrichments similar to those presented here existed over a much larger area of the WFS.

If future research demonstrates that ammonium events such as discovered during FSLE V are common, the ramifications will be well worth considering in view of the modeled importance of nitrification in the oceanic euphotic zone (Yool et al., 2007), the possible changes to surface wind-stress in a warming climate (Vecchi and Soden, 2007), the potential importance of air-sea 
ammonia fluxes (Johnson et al., 2008), and the long-standing question of the principal drivers of carbon fixation in the oligotrophic ocean.

\section{Conclusions}

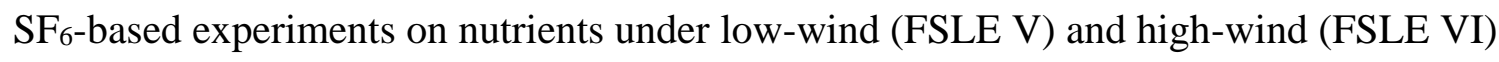
regimes on the WFS yielded results that relate to the goals in the Introduction. Ammonium seems to be the commonly enriched nitrogenous nutrient in surface WFS waters. Nitrate and nitrite are most often at background values $(0-80 \mathrm{nM})$ while ammonium enrichments can be $>5$ times background. Ammonium enrichments had spatial scales of kilometers and time scales of days. Calculations suggest that DON and PON could easily have supplied ammonium.

Surprisingly, ammonium enrichments appeared inversely linked to wind forcing in weather fronts, with low wind speeds and $\left[\mathrm{NH}_{4}^{+}\right]$peaks occurring in the same time periods. One possible explanation involves the impact of wind stress on ammonium and ammonifying organisms. Use of $\mathrm{SF}_{6}$ as dispersion indicator suggested that, depending on the duration of a wind regime, the fraction of remineralized ammonium remaining in an $\mathrm{SF}_{6}$ patch could be 2-9 times higher in a low-wind case (FSLE V) than in a high-wind case (FSLE VI). Other ammonium sources (air-sea exchange, atmospheric deposition, deep-water upwelling, freshwater input, diatom-bloom disintegration, and release from bottom sediment) appeared less likely. Although widespread occurrence of an inverse linkage between wind speed and ammonium concentration is yet to be determined, its ramifications for ammonium and carbon cycling could be significant. 
Acknowledgements

This research was supported by the US Office of Naval Research (ONR Contracts N00014-96-15024, N00014-02-1-0240, and N00014-07-1-0800 to Kent A. Fanning, John J. Walsh, and Robert T. Masserini, Jr.) and by the US National Science Foundation (NSF Award Numbers 0326268, 0752139, and 1259043 to Frank Muller-Karger, Kent Fanning, Robert Weisberg, and Yrene Astor). We thank the crew of the University of Miami research vessel F.G. Walton Smith for their support during our field studies. We also thank R. H. Weisberg and the Ocean Circulation Group in the USF College of Marine Science for the meteorological data from buoy C10.

\section{References}

Bronk, D.A., Killberg-Thoreson, L., Sipler, R.E., Mullholland, M.R., Roberts, Q.N., Bernhardt, P.W., Garrett, M., O’Neil, J.M., Heil, C.A. 2014. Nitrogen uptake and regeneration (ammonium regeneration, nitrification and photoproduction) in waters of the West Florida Shelf prone to blooms of Karenia brevis. Harmful Algae 38, 50-62.

Dortch, Q. 1990. The interaction between ammonium and nitrate uptake in phytoplankton. Marine Ecol. Prog. Ser. 61, 183-201. 
Eppley, R.W., Renger, E.H., Venrick, E.L., Mullin, M.M. 1973. A study of plankton dynamics and nutrient cycling in the central gyre of the North Pacific Ocean. Limnol. Oceanog. 18, 534551.

Eppley, R. W. and B. J. Peterson. 1979. Particulate organic matter flux and planktonic new production in the deep ocean. Nature 282, 677-680.

Gordon, L. I., Jennings, J. C. Jr., Ross, A. A., and Krest, J. M. 1993. A suggested Protocol For Continuous Flow Automated Analysis of Seawater Nutrients. In: WOCE Operations Manual. WHP office Report 90-1, WOCE report 77 No. 69/91, 1-52.

Grasshoff, K. 1976. Methods of Seawater Analysis (Verlag Chemie, Weinheim, Germany, 317 pp).

Johnson, M, R. Sanders, V. Avgoustidi, M. Lucas, L. Brown, D. Hansell, M Moore, S. Gibb, P. Liss, and T. Jickells. 2007. Ammonium accumulation during a silicate-limited diatom bloom indicates the potential for ammonia emission events. Mar. Chem. 106, 63-75.

Johnson, M. T., P. S. Liss, T. G. Bell, T. J. Lesworth, A. R. Baker, A. J. Hind, T. D. Jickells, K. F. Biswas, E. M. S. Woodward, and S. W. Gibb. 2008. Field observations of the oceanatmosphere exchange of ammonia: fundamental importance of temperature as revealed by a comparison of high and low latitudes, Global Biogeochem. Cycles. 22, GB1019, doi:10.1029/2007GB00309

Jones, R. D. 1991. An improved fluorescence method for the determination of nanomolar concentrations of ammonia in natural waters. Limnol. Oceanogr. 36, 814-819.

Kiefer, D.A. and Atkinson C.A. 1984. Cycling of Nitrogen by Plankton: A Hypothetical description based upon efficiency of energy conversion. Journal of Marine Research. 42, 655675. 
Lipschultz, F. 2001. A time-series assessment of the nitrogen cycle at BATS. Deep-Sea Res. II. 48, 1897-1924.

Liu, Y. and Weisberg, R.H. 2012. Seasonal variability on the West Florida Shelf. Prog. in Oceanog. 104, 80-98.

Masserini, R. T. and K. A. Fanning. 2000. A sensor package for the simultaneous determination of nanomolar concentrations of nitrite, nitrate, and ammonia in seawater by fluorescence detection. Mar. Chem. 68, 323-333.

Martin, A. P. 2003. Phytoplankton patchiness, the role of lateral stirring and mixing. Prog. in Oceanog. 57, 125-174.

McCarthy, J. J., W. R. Taylor, and J. T. Taft. 1977. Nitrogenous nutrition of the plankton in the Chesapeake Bay. I. Nutrient availability and phytoplankton preference. Limnol. Oceanogr. 22, 996-1011.

Mulholland, M. R., P. W. Bernhardt, C. A. Heil, D. A. Bronk, and J. M. O’Neil. 2006. Nitrogen fixation and release of fixed nitrogen by Trichodesmium spp. in the Gulf of Mexico. Limnol. Oceanog. 51, 1762-1776.

Neumann, G and W.J. Pierson. 1966. Principles of Physical Oceanography Prentice-Hall, Inc., Englewood Cliffs, NJ.

Olascoaga, M. J., I. I. Rypona , M. G. Brown, F. J. Beron-Vera, H.Kocak, L.E. Brand, G. R. Halliwell , L.K. Shay. 2006. Persistent transport barrier on the West Florida Shelf. Geophys. Res. Let. 33, L22603, doi:10.1029/2006GL027800.

Pilson, M.E.Q. 2013. An Introduction to the Chemistry of the Sea ( $2^{\text {nd }}$ Edition) Cambridge University Press, Cambridge, UK

Sarmiento, J.L. and N. Gruber. 2006. Ocean Biogeochemical Dynamics Princeton University 
Press, Princeton, N.J.

Schlitzer, R., 2013. Ocean Data View, http://odv.awi.de.

Solorzano, L. and J. H. Sharp. 1980. Determination of total dissolved nitrogen in natural waters. Limnol. Oceanogr. 25, 751-754.

Valderama, J .C. 1981. The simultaneous analysis of total nitrogen and total phosphorus in natural waters. Mar. Chem. 10, 109-122.

Vargo, G. A., C. A. Heil, K. A. Fanning, L. K. Dixon, M. B. Neely, K. Lester, D. Ault, S.

Murasko, J. Havens, J. Walsh, and S. Bell. 2008. Nutrient availability in support of Karenia brevis blooms on the central West Florida Shelf: What keeps Karenia blooming? Contin. Shelf. Res. 28, 73-98.

Vecchi, G. A. and B. J. Soden. 2007. Increased tropical Atlantic wind shear in model projections of global warming. Geophys. Res. Lett. 34, L08702, doi:10.1029/2006GL028905 Virmani, J. I. and R. H. Weisberg. 2005. Relative humidity over the West Florida Continental shelf. Monthly Weath. Rev. 133, 1671-1686.

Wanninkhof, R. 1992. Relationship between wind speed and gas exchange over the ocean. $J$. Geophys. Res. 97, 7373-7382.

Wanninkhof, R., G. Hitchcock, W. J. Wiseman, G. Vargo, P. B. Ortner, W. Asher, D. T. Ho, P.

Schlosser, M. Dickson, R. Masserini, K. Fanning, and J. Zhang. 1997. Gas exchange, dispersion, and biological productivity on the west Florida shelf: results from a Lagrangian tracer study. Geophys. Res. Let. 24, 1767-1770.

Weisberg, R. H., Y. Liu, and D. A. Mayer. 2009. West Florida Shelf mean circulation observed with long-term moorings. Geophys. Res. Lett, 36, doi:10.1029/2009GL040028.

Woodward, E. M. S. and A. P. Rees. 2001. Nutrient distributions in an anticyclonic eddy in the 
northeast Atlantic Ocean, with reference to nanomolar ammonium concentrations. Deep-Sea Res. II 48,775-793.

Yang, H., and R. H. Weisberg. 1999. Response of the West Florida Shelf circulation to climatological wind stress forcing. Geophys. Res. Let. 104, 5301-5320.

Yool, A., A. P. Martin, C. Fernández, and D. R. Clark. 2007. The significance of nitrification for oceanic new production. Nature 447, 999-1002 doi:10.1038/nature 05885 


\section{Figure Legends}

Fig. 1. Locations of $\mathrm{SF}_{6}$ injection sites for the FSLE V and FSLE VI Lagrangian experiments in the eastern Gulf of Mexico in April, 2001 and November, 2002, respectively. The SF6-labeled surface seawater tended to drift southward during the experiments, in accord with the general circulation patterns (Weisberg et al. 2009). The location of a nearby current-meter mooring with meteorological instrumentation (C10) is also shown; it is part of the West Florida Shelf mooring array maintained by the University of South Florida COMPS program

(http://comps.marine.usf.edu/). The color-coded variable quantified on the right-hand side of the figure is water depth.

Fig. 2. (a) Simultaneous time courses of dissolved ammonium and sulfur hexafluoride concentration between Julian Day 114.75 and Julian Day 114.88 in April, 2001 as the research vessel $R / V$. F. G. Walton Smith steamed at $3 \mathrm{kt}$ along a survey track starting at $26.69^{\circ} \mathrm{N}, 82.74^{\circ} \mathrm{W}$ and ending at $26.70^{\circ} \mathrm{N}, 82.75^{\circ} \mathrm{W}$ during the FSLE V experiment. (b) Surface water ammonium concentration positions for the time course in (a). Arrows denote the survey track and direction of the vessel. Data points are 200 seconds apart. Graph prepared utilizing Schlitzer (2013) Fig. 3. Time courses of wind speed (a), barometric pressure (b), and $\mathrm{NH}_{4}{ }^{+}$concentration (c) in the upper 2 meters of the ocean during the FSLE V experiment on the West Florida continental shelf between Julian Days 110 and 118.5 in April, 2001. Wind speeds, measured by an anemometer on the research vessel and corrected for ship's speed and direction, agree with the regional patterns from measurements on COMPS mooring $\mathrm{C} 10$ (Fig. 1). $\mathrm{NH}_{4}{ }^{+}$concentrations, measured on seawater flowing into the scientific seawater system of the research vessel, show the presence of maxima as "peaks" above background $\mathrm{NH}_{4}{ }^{+}$concentrations $(0-80 \mathrm{nM})$.

Fig 4. FSLE V time course of subsurface ammonium in the center of the labeled $\mathrm{SF}_{6}$ patch as determined by the location of the highest $\mathrm{SF}_{6}$ concentrations within the patch at different times. 
The black dots indicate the position of the actual samples taken, and the density structure can be seen from the isopycnal contour overlay. Graph prepared utilizing Schlitzer (2013)

Fig. 5. Time course of wind speed (a), barometric pressure (b), and $\mathrm{NH}_{4}{ }^{+}$concentration (c) in the upper 2 meters of the ocean during the FSLE VI experiment on the West Florida continental Shelf between Julian Day 310.5 and 319 in November, 2002. Wind speeds, measured by an anemometer on the research vessel and corrected for ship's speed and direction, agree with the regional patterns from measurements on COMPS mooring $\mathrm{C} 10$ (Fig. 1). $\mathrm{NH}_{4}{ }^{+}$concentrations, measured on seawater flowing into the scientific seawater system of the research vessel, show the presence of maxima as "peaks" above background $\mathrm{NH}_{4}{ }^{+}$concentrations $(0-80 \mathrm{nM})$.

Fig 6. FSLE VI time course of subsurface ammonium in the center of the labeled $\mathrm{SF}_{6}$ patch as determined by the location of the highest $\mathrm{SF}_{6}$ concentrations within the patch at different times. The black dots indicate the position of the actual samples taken and the density structure can be seen from the isopycnal contour overlay. Graph prepared utilizing Schlitzer (2013)

Fig. 7. The time variation of the natural logarithm of the mass fraction of $\mathrm{SF}_{6}\left(f_{\text {disp }}\right)$ remaining in the centers of the $\mathrm{SF}_{6}$-labeled areas of coastal water during the FSLE V and FSLE VI experiments after correction for $\mathrm{SF}_{6}$ loss due to gas exchanges with the atmosphere. The decline of $f_{\text {disp }}$ is also a measure of the relative reduction in ammonium concentrations as a result of dispersion (mixing) processes during FSLE V and VI (see text). 


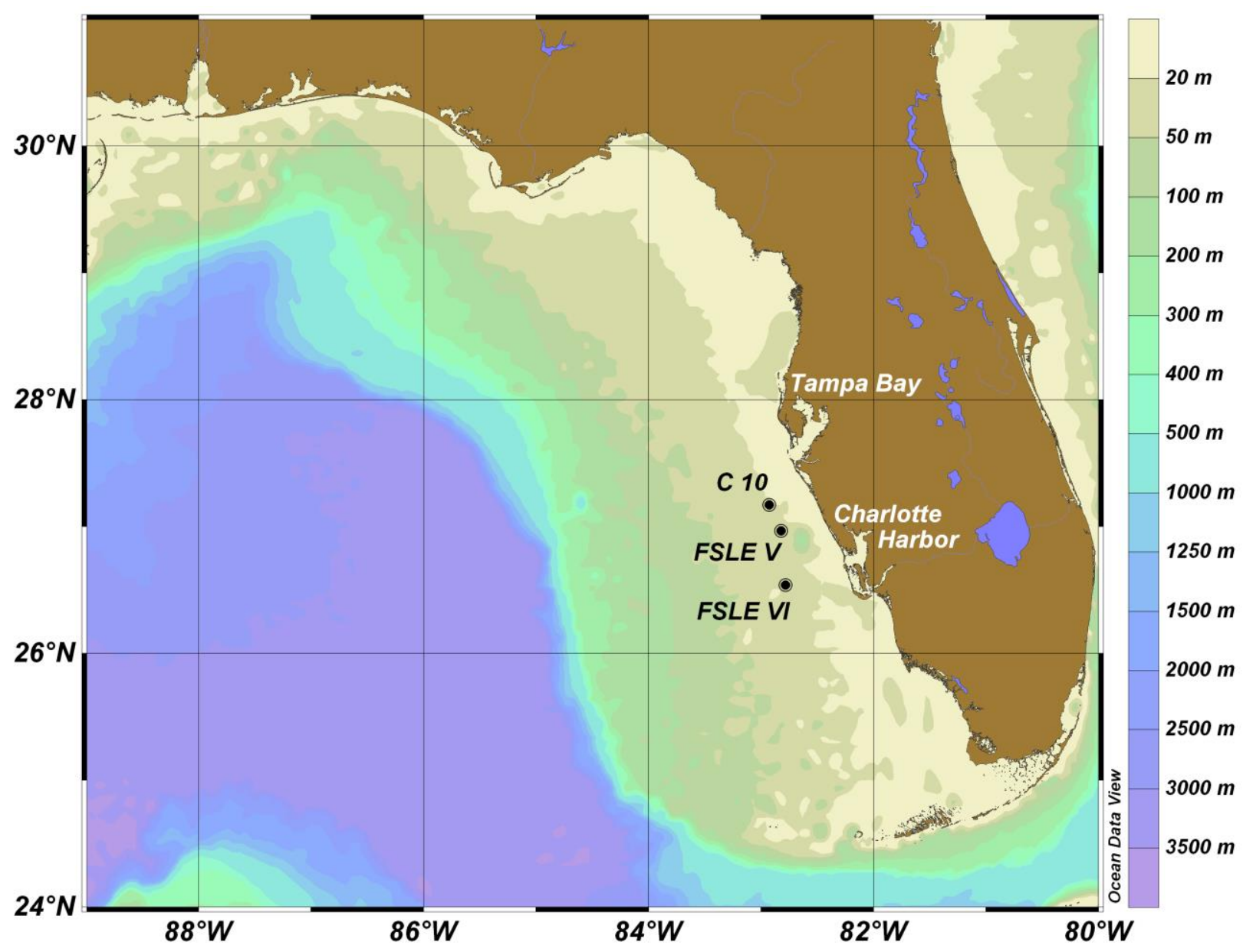

Fig. 1 


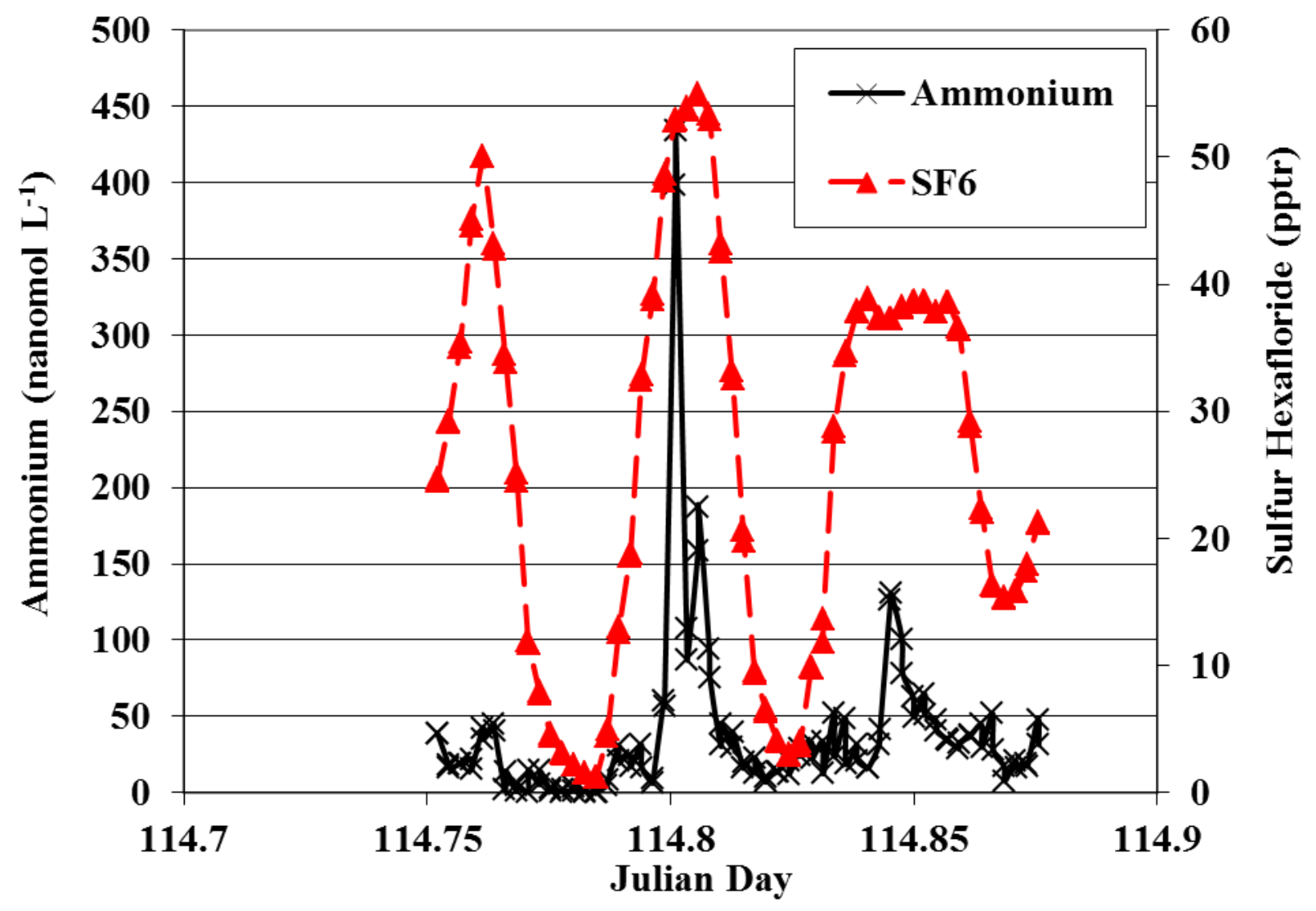

(a)

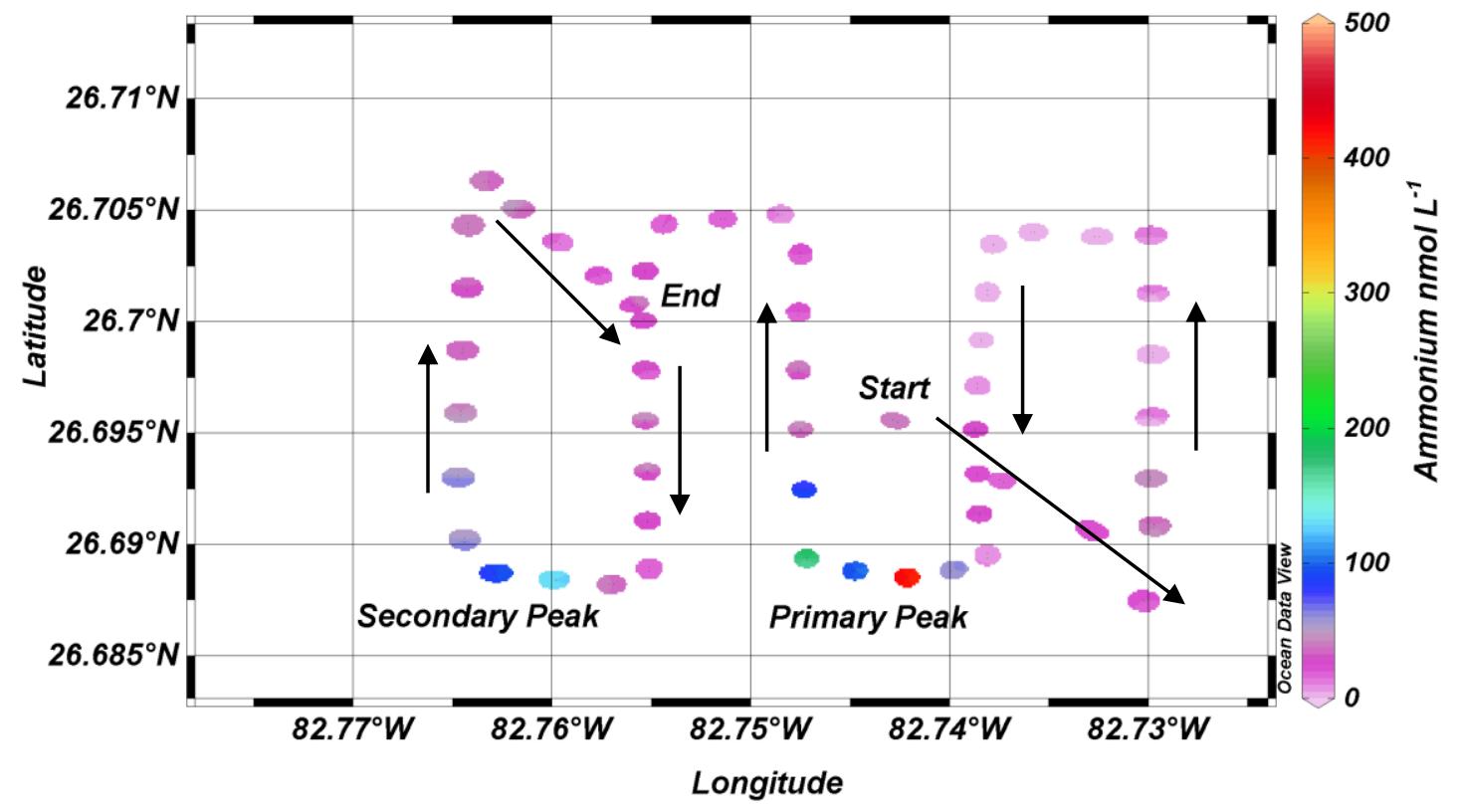

(b)

Fig. 2 


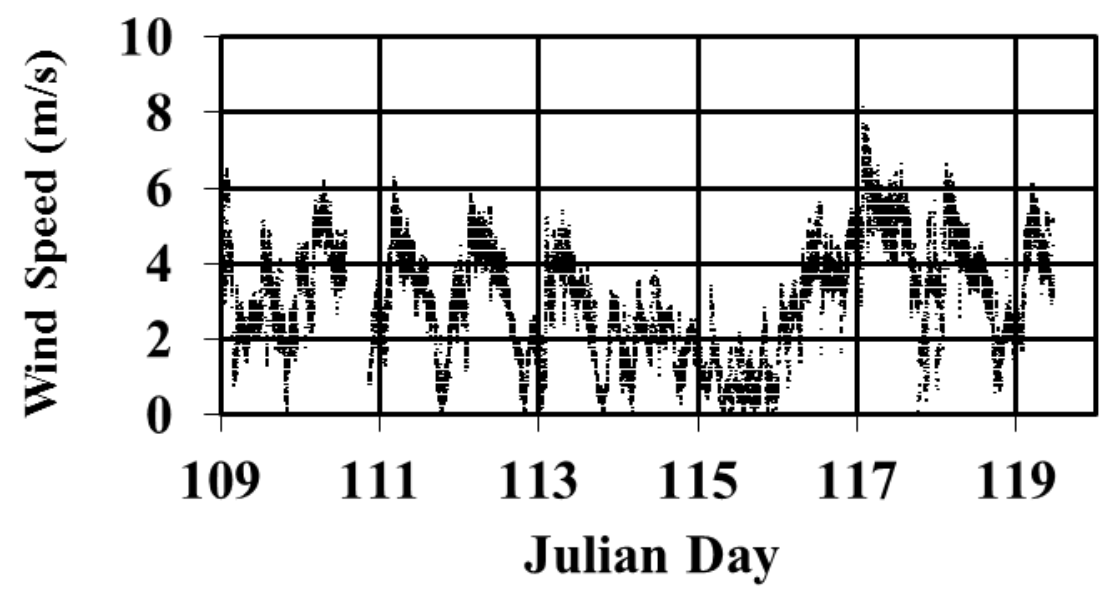

(a)

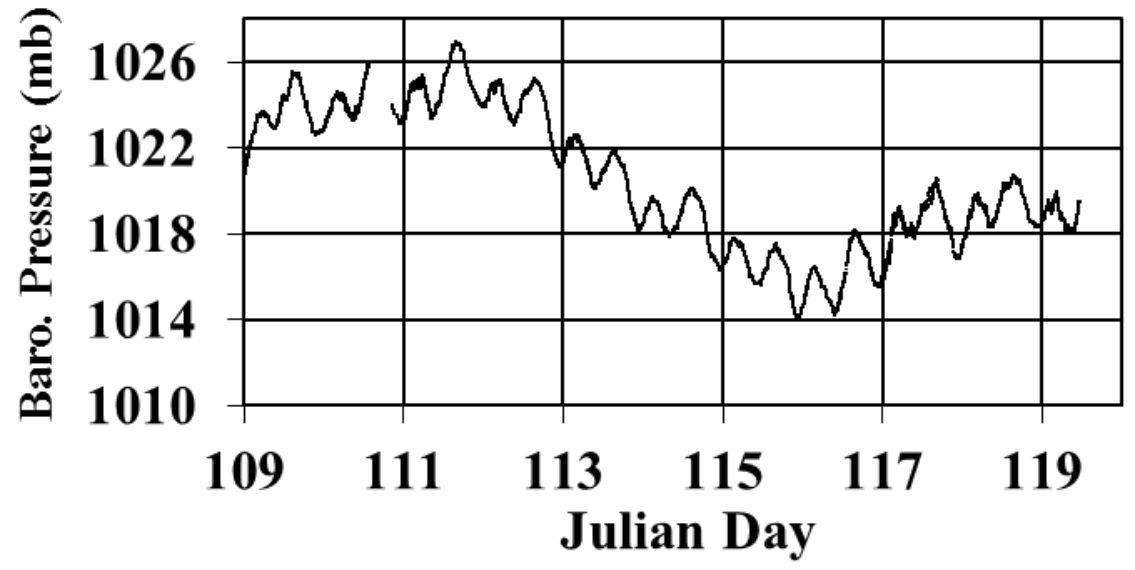

(b)

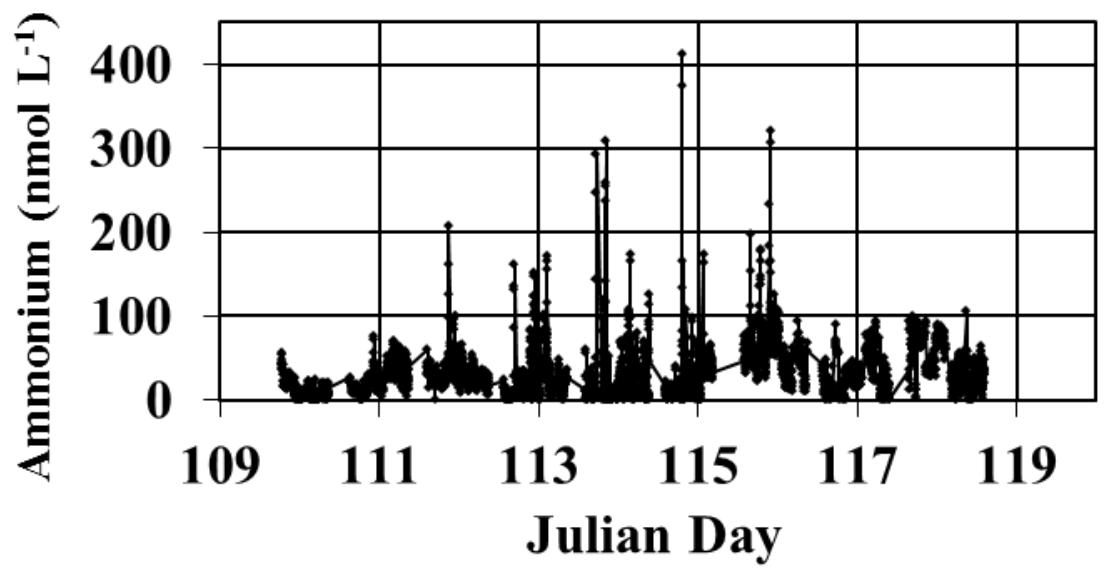

(c) 
Fig. 3

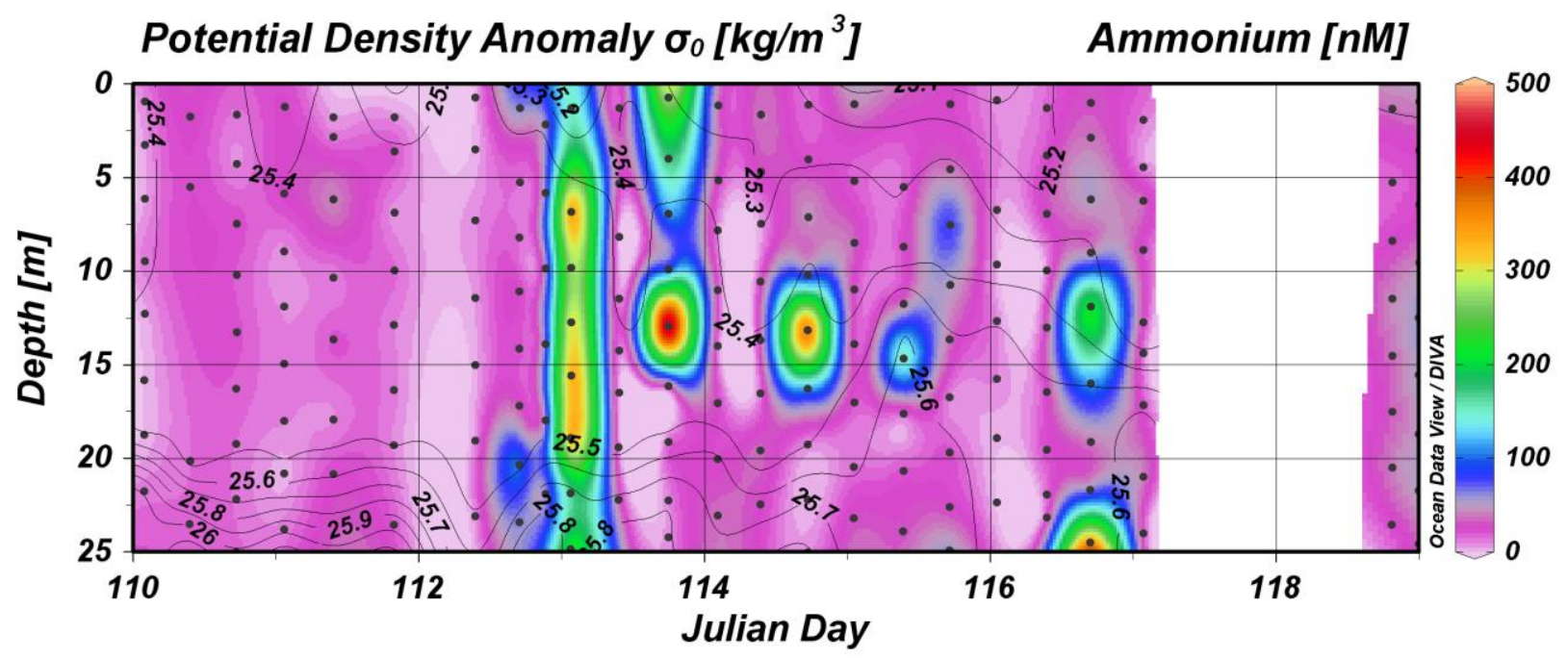

Fig. 4 


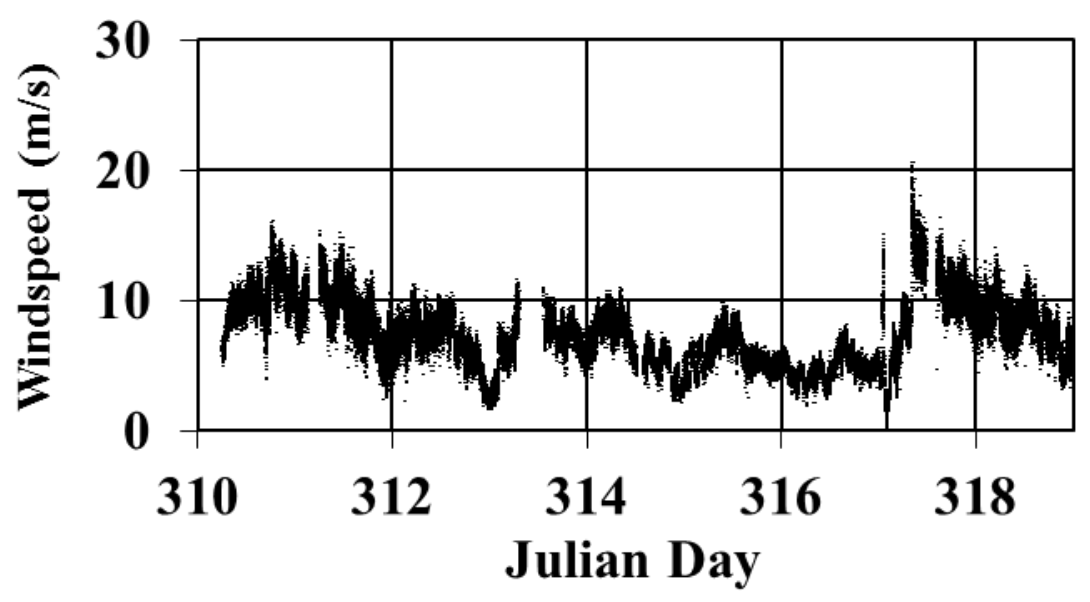

(a)

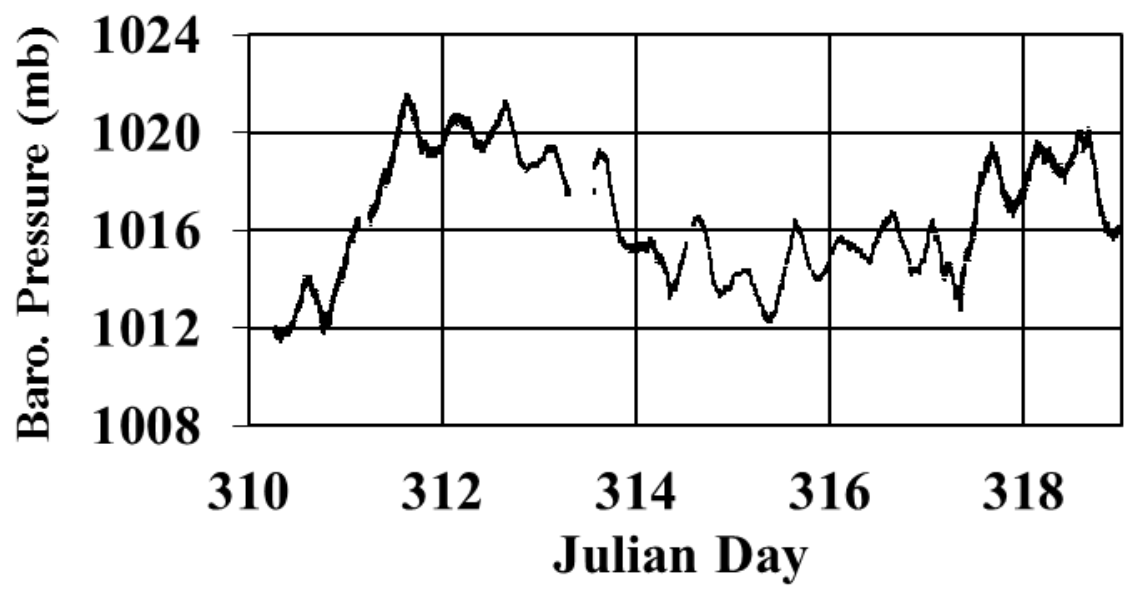

(b)

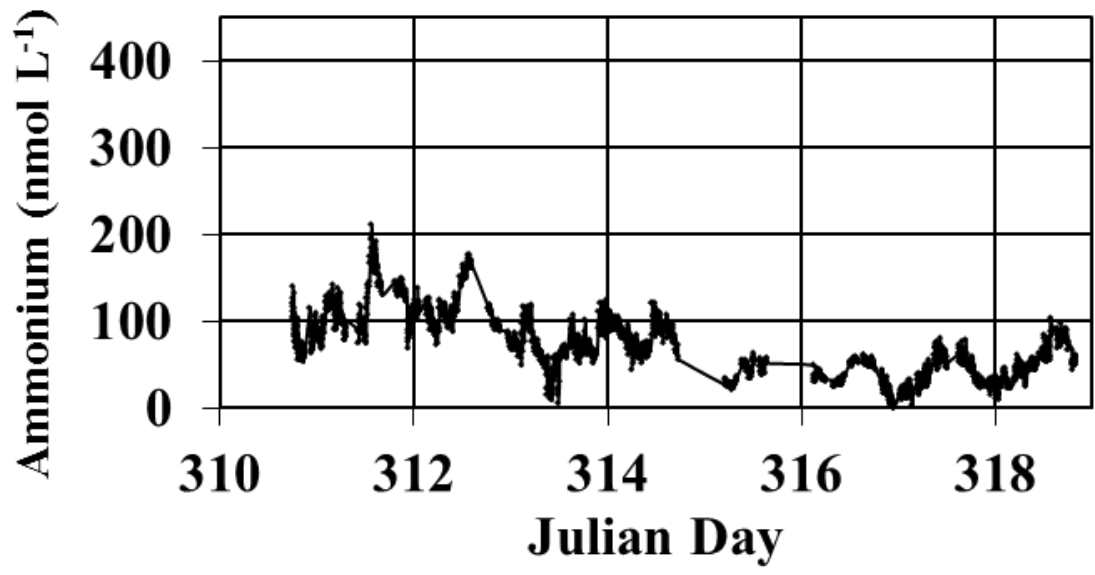

(c)

Fig. 5 


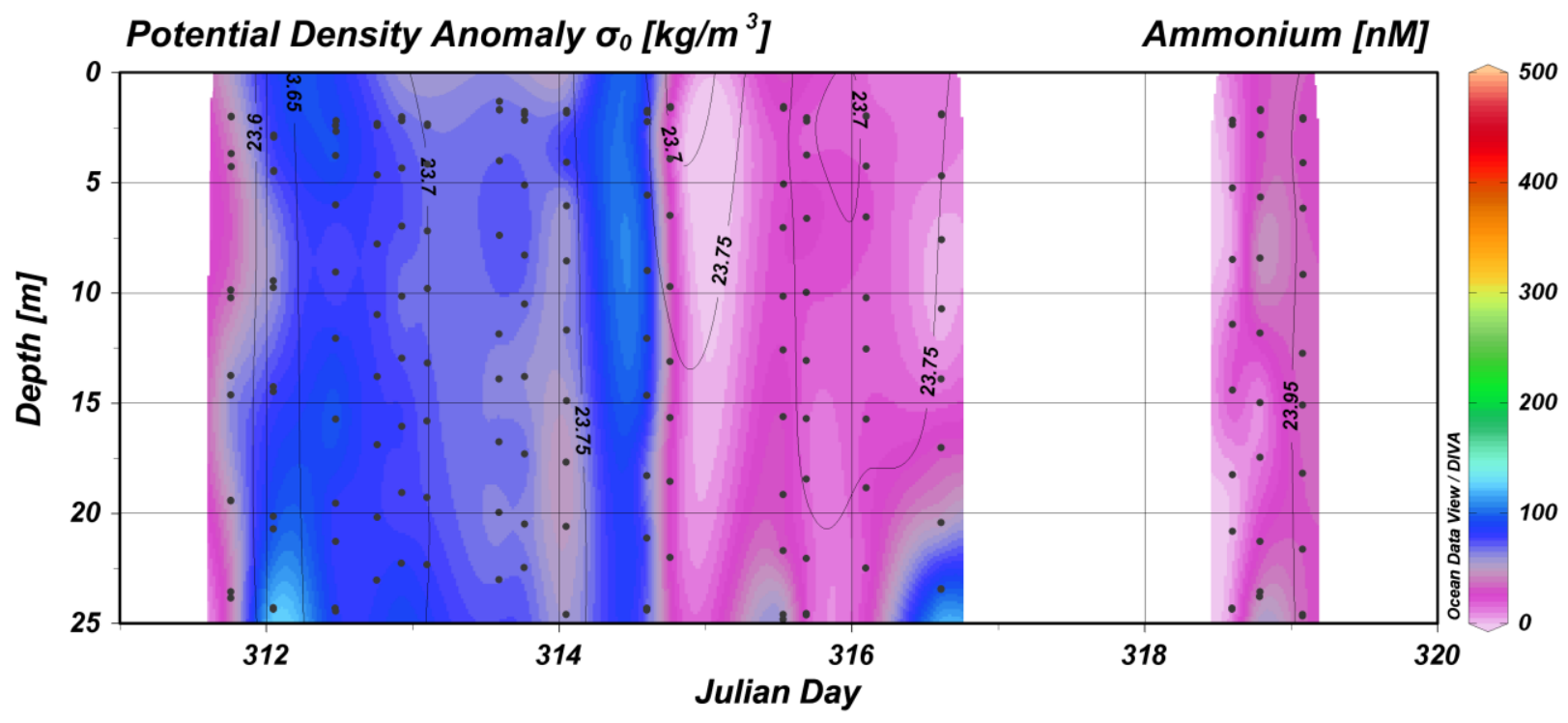

Fig. 6 


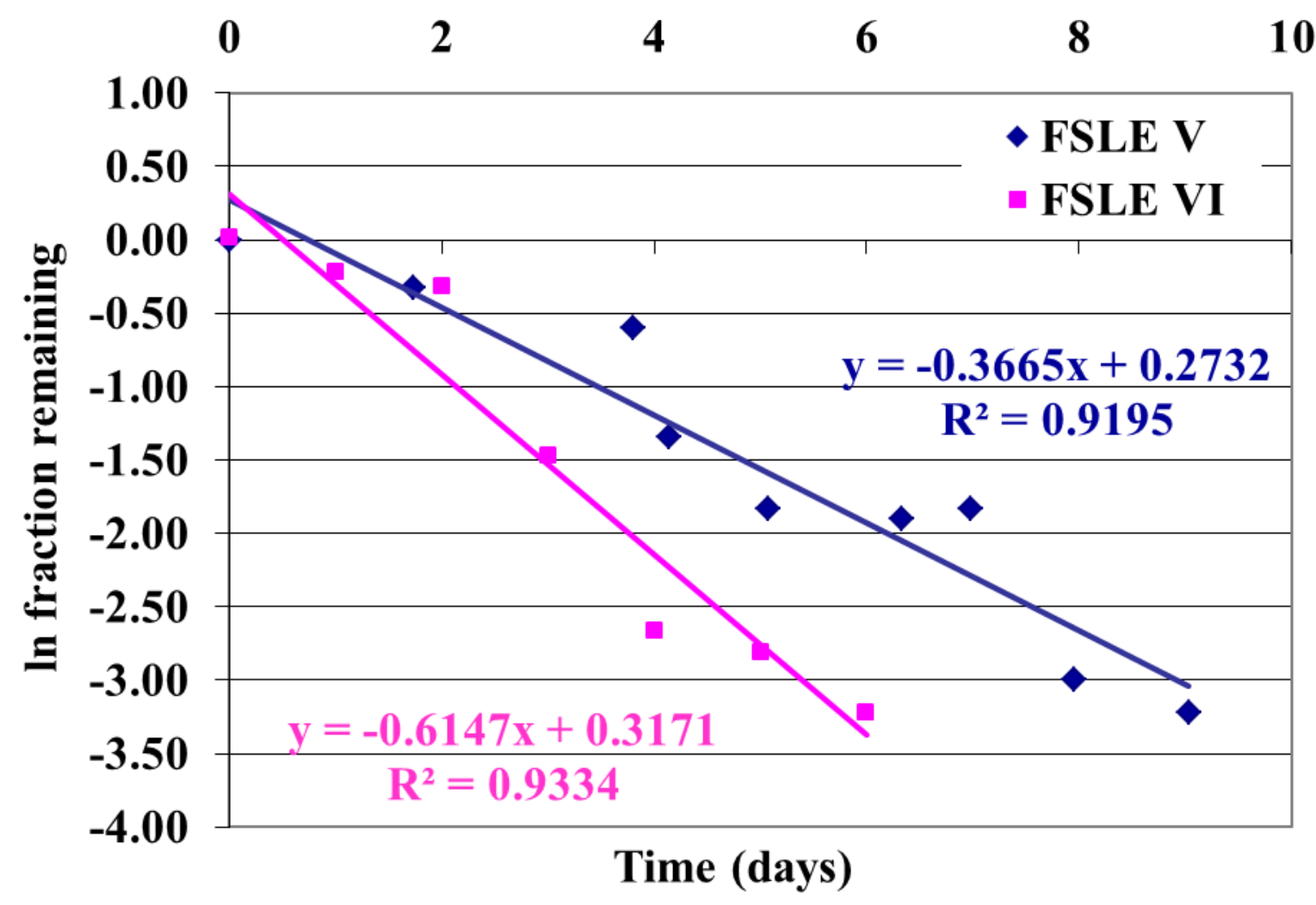

Fig. 7 
Table 1. Single factor ANOVA analysis of five parameters measured during the FSLE V and FSLE VI Lagrangian experiments in the drier, cooler season on the West Florida Shelf. Beginning locations for FSLE V and FSLE VI are shown in Fig. 1. $\mathrm{N}$ is the total number of samples of each parameter for FSLE V and FSLE VI combined. $F_{\text {critical }}(99.9 \% \mathrm{CI})$ is the theoretical value of the Factor at the 99.9\% confidence level if two populations of the same parameter are not statistically different. A Factor $>F_{\text {critical }}$ means the populations are statistically different.

\begin{tabular}{|c|c|c|c|c|}
\hline Parameter & $\mathrm{N}$ & $\mathrm{F}_{\text {critical }}(99.9 \% \mathrm{CI})$ & Factor & Conclusion \\
\hline Wind Speed & 127,802 & 10.83 & 124,127 & Different \\
\hline Salinity (water column) & 417 & 10.83 & 6.08 & Same \\
\hline Temperature (water column) & 417 & 10.83 & 15,022 & Different \\
\hline Chlorophyll (water column) & 417 & 10.83 & 9.43 & Same \\
\hline Total Ammonia (upper 2 m) & 6957 & 10.83 & 3622 & Different \\
\hline
\end{tabular}

